\title{
Revisitando a "Guerra ao Terror": terrorismo e política externa norte-americana no pós-Guerra Fria
}

Revisiting the "War on Terror": terrorism and US foreign policy in the post-Cold War

\section{Leandro Carlos Dias Conde ${ }^{1}$}

\section{RESUMO}

A proposta deste trabalho é discutir os novos contornos no sistema internacional quanto ao papel de superpotência dos Estados Unidos no pós-Guerra Fria. Tendo como foco o advento da "guerra ao terror" e suas implicações para a ordem mundial emergente no século XXI. Assim como lançar luz ao papel dos EUA na economia política internacional contemporânea, como instrumento de política externa.

Palavras-chave: Política externa; Guerra ao Terror; Pós-Guerra Fria.

\begin{abstract}
The purpose of this paper is to discuss the new contours in the international system as the US superpower role in the post-Cold War. Focusing on the advent of the "war on terror" and its implications for the emerging world order in the twenty-first century. As well as shed light on the US role in contemporary international political economy, as an instrument of foreign policy.
\end{abstract}

Keywords: Foreign Policy; War on Terror; Post-Cold War.

\section{INTRODUÇÃO}

O governo George W. Bush buscou construir uma ampla coalizão de países contra o terror, buscando o apoio de seus aliados costumeiros, mas também de China e Rússia, países com direito a veto no Conselho de Segurança da ONU. Os EUA buscavam um consenso na "comunidade internacional" no conflito contra terrorismo, o que levou a uma política de corrupção, ameaças, chantagens, a fim de instalar suas bases militares, utilização do espaço aéreo e acesso a informação confidencial dos países (Bianchi, 2003). No entanto, a única conexão da invasão ao Iraque com o terrorismo transnacional

\footnotetext{
${ }_{1}^{1}$ Mestrando em Ciência Política pelo Instituto de Estudos Sociais e Políticos da Universidade do Estado do Rio de Janeiro (IESP/UERJ). Rio de Janeiro/RJ, Brasil. leandrocdconde@gmail.com

Conjuntura Global, Vol. 4, n. 1, jan./abr., 2015, pp. 70-83. 
foi que esta contribui para o exponencial crescimento do terrorismo. Desmistificando a relação de Saddam com a rede terrorista Al Qaeda², diz-nos Chomsky (2004, p. 25): “[...] o suposto vínculo de Saddam Hussein e Osama Bin Laden, na verdade seu inimigo figadal, baseava-se em provas sem credibilidade que já haviam sido descartadas por observadores competentes".

Citando Kenneth Waltz, Chomsky (2004) argumenta que o uso do poder militar norte-americano para solapar um inimigo num país indefeso, claramente, produz o ódio daqueles que sofrem com o ataque, assim como o desejo por vingança - que pode ser compartilhado com outros - e a busca de algo, entre aqueles países ameaçados, que impeça que o mesmo ocorra com eles. Assim, recorrer às armas de destruição em massa é extremamente racional por parte dos países que se sintam acuados, a política externa norte-americana que busca combater o terrorismo e a proliferação de Armas de Destruição em Massa (ADM), acaba a estimular a proliferação dos mesmos. Os estrategistas de Washington têm plena consciência dessa questão, mas a possibilidade sempre presente de proliferação é usada pela política doméstica e pela política interna, acionando o medo do terrorismo e a das ADM sempre que necessário a fim de garantir a obediência dos aliados e dos mais fracos, e, por meio das invasões, demostrar a capacidade sempre disponível de reação.

Muitos aludem as intervenções humanitárias como "primazia do direito internacional", estes advogam o direito internacional como ordenador das relações internacionais, retomando o vetusto modelo kantiano. Porém, ao analisar as intervenções humanitárias, torna-se claro que as regras do direito internacional privilegiam as potências imperialistas, o direito internacional é manejado ao bel prazer da potência imperial norte-americana, a fim legitimar, à luz das leis internacionais, suas incursões militares. Entretanto, se aceitarmos a estratégia norte-americana a partir de sua retórica dos princípios elevados, na primeira mirada da situação no Iraque, perceberemos que os resultados são, definitivamente, outros.

\footnotetext{
2 Al Qaeda, criada no Paquistão, durante muito tempo presente no Afeganistão, depois retornando ao Paquistão, oriunda, principalmente, das brigadas internacionais na guerra afegã, seu significado no árabe é "a base", sua rede articula-se de forma dispersa e descentralizada, organizando células locais somente para organizarem atentados, seus integrantes são todos homens e muçulmanos e sunitas, o número de integrantes não é preciso, mas situa-se em números bem menores do que os milhares que a retórica dos Estados Unidos apresenta, seus dados não são precisos (Mann, 2006).

Conjuntura Global, Vol. 4, n. 1, jan./abr., 2015, pp. 70-83. 
[...] os atentados contra as torres gêmeas de Nova York provocaram cerca de 3.000 mortos. Em quatro anos, a guerra do Iraque, desencadeada a pretexto (inteiramente falacioso, voltamos a insistir) de punir os cúmplices dos atentados, causou a morte de um número sensivelmente mais elevado de iraquianos, estimado em 2007, entre 60.000 (pelo Irak Body Count) e 600.000 (pela revista de medicina, The Lancet), ou seja, entre 20 e 200 iraquianos por cada norte- americano morto. (Todorov, 2010, p. 131).

\section{O "novo" inimigo}

0 terrorismo enquanto novo "inimigo" não se identifica com nenhum estado nacional, não possui um exército, e não há nenhuma complementariedade seja econômica ou militar como havia com a União Soviética. "Ele é universal e ubíquo, um inimigo tipicamente imperial, da humanidade, e não de algum estado em particular (Fiori, 2007, p. 103)”. As implicações do combate a este tipo de ameaça são as maiores possíveis, pois é um inimigo que os Estados Unidos identificam, marcam, delimitam e atacam. Ele pode estar em qualquer canto do globo e agir de diversas formas, ele é um inimigo que não tem fim, que não se derrota, numa guerra de prolongamento "infinito". A mutabilidade deste mal definido inimigo está presente nesta primeira década do século XXI, ele já esteve em diversos estados e, por esta razão, estes sofreram a desgraça de serem invadidos. 0 que começa com a Al Qaeda, e o regime talibã no Afeganistão, depois assume outras definições, segundo Fiori (2007), de "redes terroristas", englobando também ameaças mais tradicionais como o "eixo do mal" e os "estados produtores de armas de destruição em massa".

\footnotetext{
Uma ameaça, portanto, que pode ser nuclear, mas também pode ser cibernética, biológica, química e pode estar no ar, na terra, na água, nos alimentos, enfim, em centenas de veículos ou lugares diferentes. Neste sentido, nesta guerra escolhida pelos Estados Unidos, tudo pode se transformar numa arma, em particular as inovações tecnológicas dos próprios americanos. E tudo pode se transformar num alvo, em particular as coisas mais prezadas e desprotegidas dos norte-americanos. (Fiori, 2007, p. 104).
}

Furtando-se de obedecer ao direito internacional, os EUA empreendem guerras preventivas e não preemptivas, como pode aparecer nos discursos oficiais. Neste caso, mais uma vez, os Estados Unidos deixam claro que a força é aquela que faz a lei, o que é claramente um desalento àqueles países que não dispõem de força semelhante para 
fazerem o mesmo, porém, o desalento torna-se algo bem pior quando estes países estão no caminho de Washington.

\begin{abstract}
Unidos de empreender "guerra preventiva" quando desejar: Preventiva e não preemptiva. Uma guerra preemptiva poderia se encaixar na seara do direito internacional. [...] As justificativas para a guerra preemptiva, porém, quaisquer que sejam, não se aplicam à guerra preventiva, principalmente da forma como tal conceito é interpretado por seus atuais partidários: o emprego de força militar para eliminar uma ameaça imaginada ou fabricada, o que torna até o termo prevenção excessivamente benevolente. (Chomsky, 2004, p. 18).
\end{abstract}

A opção pelos ataques preventivos tende a se estender também para as outras grandes potências, o que cria um imenso barril de pólvora, pois não há consenso em torno do que são os terroristas para cada país. Cada um deles define, dentro de sua estratégia de defesa, quem poderiam ser considerado terrorista e passível de ataques preventivos. Fiori (2007) considera a estratégia da luta contra o terrorismo internacional insustentável no médio prazo, estando esta longe de produzir o tipo de equilíbrio bipolar em longo prazo produzido durante a Guerra Fria. Para ele, as resistências contra este tipo de estratégia devem surgir dentro do núcleo do capitalismo, ou seja, das grandes potências.

De acordo com Chomsky (2004), a definição de terrorismo nos Estados Unidos data do período Reagan, mas a definição na atual guerra contra o terrorismo, a guerra sem fim de George W. Bush, não faz correspondência com sua precursora. Isto se deve as definições de terrorismo e contraterrorismo - que pode ser lido como contrainsurgência, conflito de baixa intensidade - serem as mesmas, porém, quando são os EUA que fazem uso do contraterrorismo por terem sido vítimas deste em seu território, as definições anteriores deixam de ter validade. Ora, segundo a retórica dos discursos oficiais, os Estados Unidos não praticam terrorismo, apenas se defendem dos sanguinários terroristas que desejam a todo custo o fim da América. Sim, pois os mais fortes apenas se defendem dos mais fracos, terrorismo é praticado pelos fracos. Claro, esse posicionamento não é exclusivo de Washington, qualquer país classifica de contraterrorismo o terrorismo que emprega.

Entretanto, não há definições fechadas de terrorismo, de terrorismo internacional e de resistência, o que buscamos fazer é mostrar como as definições são diferentes entre 
a grande maioria dos países do globo e os Estados Unidos e seus aliados. "A despeito da falta de clareza e da nítida discordância entre Estados Unidos-Israel e o mundo, as definições oficiais americanas de terrorismo são bastante adequadas às finalidades momentâneas (Chomsky, 2004, p. 193)".

Para as Nações Unidas, é legítima a resistência a regimes que privam a liberdade e a independência, "regimes colonialistas e racistas e ocupação estrangeira", e esta definição foi rejeitada pelos Estados Unidos diante da resolução da ONU de 1987 que tratou do tema, pois esta era voltada contra seus aliados colonialistas e racistas à época, o regime do Apartheid da África do Sul, apoiado por Washington.

Assim, diante do posicionamento norte-americano, a distinção entre resistência e terrorismo era propositalmente nublada. No caso sul-africano, implicou na condenação ao uso da violência contra o regime racista, na prisão de Nelson Mandela, considerado pela Casa Branca como notório terrorista. Da mesma forma, não era possível aceitar a resistência do povo do Timor Leste ao regime colonial Indonésio, do povo curdo pelo extermínio sofrido na Turquia, entre outros muitos casos de atrocidades. Ao consideramos a guerra justa, como tanto os Estados Unidos o fazem, não podemos perder de vista o princípio da universalidade, mas ao que parece este princípio vem sendo deixado de lado. A visão do mundo maniqueísta reduz as complexidades das relações internacionais ao bem e mal, amigo e inimigo - por mais transitório que sejam essas posições, ter um inimigo, alguém para imputar a culpa facilita o caminho para a guerra.

\section{0 inimigo Islã}

Segundo Todorov (2010), a teoria do choque das civilizações de Samuel Huntington (1997), que, a despeito dos seus simplismos, popularizou-se e ganhou o mundo, é retomada com força após os atentados de 11 de setembro. Citando as conferências do Conselho Nacional de Informação (National Intelligence Council) em 2000, do qual fez parte, Mann (2006) chama atenção que o relatório produzido já alertava para o fato de que a globalização, festejada no centro do capitalismo e vendida à periferia como processo inevitável, não beneficiaria a todos e os que ficassem fora da festa global representariam grandes ameaças neste início do século XXI. Obviamente, tal 
relatório da Agência Central de Inteligência (CIA - ingl.) esconde o papel ativo da política externa norte-americana para a proliferação dessas "ameaças" e imputa toda a culpa do fracasso econômico e exclusão do processo de globalização aos países da periferia por não aplicaram as reformas necessárias e resistirem à liderança norte-americana, estes países são classificados por Washington como "estados fracassados".

A guerra global entre o islã e o ocidente, camuflada sob o manto da guerra contra o terrorismo, alimentou a ânsia de guerra dos dois lados, serviu de motivação para o recrutamento de novos jihadistas de um lado e da invasão ao Iraque do outro lado. 0 medo do islã não é novo ao ocidente, mas, especialmente, devido ao esforço do governo George W. Bush, de engendrar a face do terror no islã, a situação toma níveis de esquizofrenia, neste momento, diz-nos Todorov, "a teoria do choque das civilizações é adotada por todos aqueles que têm interesse em traduzir a complexidade do mundo em termos de confronto entre entidades simples e homogêneas [...] (2010, p. 109)”. A ênfase nas origens religiosas ou culturais dos conflitos não está errada, contudo obscurece que os objetivos perseguidos não são religiosos, "a motivação religiosa transforma a busca do interesse em paixão (2010, p. 111)”.

Nesse prisma, os ataques aos EUA decorreriam de questões étnicas, religiosas e culturais, que residem na dificuldade dos "outros" em conviverem com as diferenças, argumento que não é nada novo, Samuel Huntington já o anunciara tempos atrás. Esclarece-nos Mann (2006, p. 223): “[...] É uma forma simplista e etnocêntrica de desprezar quaisquer mágoas causadas pela nossa agressão. [...] Não odeiam a nossa cultura, a nossa democracia nem a nossa riqueza; somente a nossa política externa".

\footnotetext{
Quando uma multidão, dominada pela raiva, exige a morte de uma professora primária inglesa que teria ofendido o Profeta - esse caso ocorreu no Sudão, em novembro de 2007 -, o verdadeiro objetivo consiste na defesa, não propriamente do islã, mas da honra que, segundo esses manifestantes, tem sido vilipendiada há muito tempo pelas potências ocidentais. (Todorov, 2010, p. 111).
}

0 mundo tem a sorte de que as guerras contemporâneas não sejam entre civilizações estanques, como previa Huntington, pois a solução desta seria o extermínio ou a escravidão da outra civilização. Os reais motivos das guerras são obnubilados pela 
teoria do choque das civilizações, cujas verdadeiras razões são de motivações políticas, sociais, econômicas e demográficas.

\begin{abstract}
Não há necessidade de evocar o islã ou o choque das civilizações para explicar o motivo pelo qual os afegãos ou os iraquianos resistem às forças militares ocidentais que ocupam seus territórios; nem de falar de antijudaísmo ou de antissemitismo para compreender as razões pelas quais os palestinos não se regozijam com a preocupação israelita de suas terras; nem de citar os versículos do Alcorão para conferir um sentido à reações dos libaneses que, em 2006, oferecem resistência à destruição das infraestruturas do país. (Todorov, 2010, p. 116).
\end{abstract}

De acordo com Fiori, o ataque norte-americano ao Iraque teve implicações geopolíticas no Oriente Médio, mas também no norte da África e na Ásia Central, ele produziu um rearranjo nas forças políticas e militares na região, mas não do lado norteamericano, mas da resistência ao ocidente. "Ao derrotar os sunitas e entregar o governo do Iraque aos xiitas, os Estados Unidos fortaleceram indiretamente o Irã e o nacionalismo religioso, que são seus principais adversários no Oriente Médio (Fiori, 2008, p. 41)". Estes acontecimentos não implicam na perda da influência norteamericana no Oriente Médio, muito menos de sua presença militar, mas na perda da posição de único árbitro da região, tendo que lidar com uma "pressão competitiva" na região, na qual novas potências também vêm se inserindo, em particular a China. No caso da Rússia, é o retorno de presença ativa na região, deixada de lado com o fim da União Soviética. Os problemas na região parecem sem fim e insolúveis, o clima de medo é mantido pela disposição norte-americana de empreender ataques preventivos, quando necessários, ou seja, a estratégia "contenção global preventiva” reforça o clima de medo.

[...] a sobreposição dos conflitos religiosos, com as divergências territoriais e a abundância de recursos energéticos, manterá o Oriente Médio no epicentro das tensões internacionais, e deve transformar seu território no espaço preferencial de experimentação de alianças e de todo tipo de armamento "assimétrico" e convencional produzido pelas velhas e novas grandes potências. (2008, p. 42).

Todorov lança mão do conceito de "racionalidade instrumental", ao considera-la ser própria de todos os seres humanos, para analisar ambas as retóricas, a de Washington e a de Osama Bin Laden, que buscam adequar os meios aos fins pretendidos. 
Assim, os ataques de 11 de setembro para aqueles que o perpetraram, tratou-se de um aviso aos Estados Unidos e ao ocidente de que suas ações imperialistas na periferia teriam consequências, mesmo que o as custa de milhares de inocentes. Da mesma forma, a retórica da política externa norte-americana apresentou a invasão ao Iraque como passo decisivo na vitória da guerra ao terror, na qual os EUA levariam àquele país os valores ocidentais e libertaria do jugo do tirano e sanguinário Saddam Hussein, quando o resultado da invasão é a catástrofe da guerra civil no país. Sem dúvida há uma desproporcionalidade no uso de poder, não se pode comparar o poder militar norteamericano com o das redes de terrorismo transnacional, mas estas mostraram que possuem capilaridade para desafiarem o ocidente com ações terroristas.

Neste sentido, para Todorov, a "guerra ao terror" reforça o mundo maniqueísta da retórica norte-americana e ocidental, o termo "islamo-fascismo" diz muito do período, ele está presente tanto entre os conservadores europeus quanto os norteamericanos e durante o governo Bush, ele também está presente nos intelectuais e políticos ligados à administração, com passe livre na Casa Branca. 0 clima de medo e hostilidade criado após os atentados de 11 de setembro também afetam aos que resistem ao establishment, estes políticos acumulam perdas eleitorais e enfrentam perseguição política, paradoxalmente, no país das liberdades.

Os partidários de atitudes mais tolerantes são estigmatizados como "multiculturalistas" e assimilados a colaboracionistas, para não dizer, traidores. Essa visão do mundo foi adotada pelos círculos dirigentes dos Estados Unidos que declararam "guerra ao terrorismo" (Todorov, 2010, p. 118).

A retórica civilizacional e multicultural do choque das civilizações, fortemente presente na caracterização do islã como inimigo do ocidente, também está longe de explicar as motivações de Osama Bin Laden. Os motivos que movem Bin Laden residem no imperialismo norte-americano, que se situa na posição de um islamita antiimperialista, que não odeia o ocidente pela sua cultura e seus valores, mas pelo que este produziu de mortes e destruição durante a dominação colonial e pela presença e interferência dos Estados Unidos. Osama Bin Laden, segundo Michael Mann, 
A partir de 1996, deu sempre três razões para atacar os EUA: a ocupação militar dos EUA na Arábia Saudita (às vezes de toda a Península Arábica); o apoio dos EUA a Israel/aos sionistas/aos judeus; e a invasão do Iraque pelos EUA em 1991 e o posterior bombardeio e a fome impostas às suas crianças. Mais tarde acrescentou a invasão norte-americana do Afeganistão e a invasão do Iraque. [...] uma viseira etnocêntrica para não ter de discutir as coisas que interessam aos adversários muçulmanos dos EUA. Bin Laden condenou a exploração econômica, só que não pelos capitalistas (ele é um deles), mas sim pelos imperialistas que tomam violentamente a terra e a propriedade pela força das armas. [...] Apesar da retórica religiosa e dos meios sangrentos, Bin Laden é um homem racional. Há uma razão simples para atacar os EUA. 0 imperialismo americano. Enquanto os Estados Unidos buscarem controlar o Oriente Médio, ele e pessoas como ele serão seus inimigos. (2006, p. 232-234)

A retórica norte-americana superestimou a Al Qaeda e apresentando-a como uma rede altamente articulada mundialmente, com grande apoio entre os povos islâmicos. Contudo, a Al Qaeda tem, na verdade, pouco poder de fato e sérias dificuldades de articulação e não consegue unir os movimentos de contestação ao redor do mundo. Ocorre que a guerra ao terror, revela Mann, pode ajudar a tarefa da Al Qaeda de se unir aos demais grupos terroristas, islâmicos e não-islâmicos.

A guerra sem fim também tem seus propósitos na política doméstica de Washington, usada para fomentar o clima de terror, produzindo o medo na população norte-americana e buscando justificar os custosos programas militares e o cerco as liberdades civis. A guerra do Iraque também serviu como "efeito demonstração", diz-nos Wood, através do terror os EUA mostram aos inimigos, o que pode lhes acontecer em caso de seguirem desafiando o ocidente. Assim, ressalta Wood:

[...] o estado de guerra tem o objetivo de criar o clima político interno apropriado dentro dos EUA, os aliados são atraídos a sua órbita hegemônica através de sua participação em pactos e alianças, e por meio de uma supremacia militar tão amedrontadora e custosa que outras grandes potências econômicas não veem sentido no esforço de tentar igualá-la. Em todos os casos, o objetivo supremo é demonstrar e consolidar o domínio norte-americano sobre o sistema de múltiplos estados. (2003, p. 198). (Tradução nossa).

Os atentados de 11 de setembro e a diplomacia doméstica de difusão do medo na população norte-americana logrou que os Estados Unidos caminhassem cada vez mais para um Estado policial, o que se materializa quando qualquer indivíduo considerado "suspeito" pode ser preso sem acesso a advogados até que as autoridades decidam que ele não é mais um suspeito. Isto é, "Um combatente inimigo pode ser qualquer um que os Conjuntura Global, Vol. 4, n. 1, jan./abr., 2015, pp. 70-83. 
Estados Unidos resolvam atacar, sem provas convincentes, conforme admite Washington (Chomsky, 2004, p. 33)".

A isso, soma-se o imenso aparato de câmeras de vigilância instaladas aos milhares e controles de imigração extremamente invasivos. Todorov ressalta os perigos do "medo" desempenhar papel de paixão dominante, seu uso corrente para autorizar e justificar as ações desumanas: o medo pode tornar-se incontrolável, produzindo excessos irreparáveis. A política do medo no pós-Guerra Fria tornou-se mais complicada com o fim da União Soviética, não há mais o inimigo clássico, contudo, a importância do medo para a fabricação do consenso na opinião pública continua sendo de fundamental importância, o 11 de setembro define claramente as proporções do uso do medo, a partir dele "[...] tem sido perpetradas, entre outras iniciativas, detenções ilegais e atos de tortura, cuja simbologia pode ser encontrada, atualmente, em denominações como Guantánamo, Abu Ghraib, Bagram (2010, p. 15)”.

Todorov (2010) lembra-nos que a tortura está presente desde a antiguidade, ao longo da história, ela tornou-se de uso corrente em regimes totalitários, ditaduras militares, países instáveis dominados por grupos paramilitares, países em guerra civil ou mesmo em contexto de guerra contra outro, em suma, sua prática não coaduna com os ideais democráticos, com a defesa e garantia dos direitos humanos, assim, num esforço internacional os atos de tortura passaram a serem considerados ilegais, sobretudo com a Declaração dos Direitos Humanos, em 1948, nas Convenções de Genebra, em 1949, e na Convenção das Nações Unidas, em 1984. Obviamente,

\footnotetext{
a assinatura de tais convenções não impediu que os governos de diversos países tivessem feito uso da tortura quando esta lhes pareceu necessária para atingir seus objetivos; no entanto, eles não deixaram de recorrer a todos os meios para dissimular tais práticas e negar publicamente sua aplicação. A interdição não é, portanto, respeitada estritamente, nem os atos de barbárie desapareceram como por encanto; mas um ideal de civilização foi estabelecido, exercendo um efeito de moderação e diminuindo consideravelmente o número de violências perpetradas. (Todorov, 2010, p. 134).
}

No entanto, a questão da tortura ganha a cena novamente, não na mídia de massa, obviamente, mas, especialmente, nos círculos intelectuais, uma mudança silenciosa estava em curso, desencadeada pela declarada necessidade norte-americana de recorrer à tortura após os atentados de 11/9, com a escusa da segurança nacional. As torturas já Conjuntura Global, Vol. 4, n. 1, jan./abr., 2015, pp. 70-83. 
vinham sendo praticadas, de fato nunca cessaram, mas em meio ao clima de medo insano após os atentados e a aprovação das leis de exceção, o governo norte-americano se vê numa situação, minimamente, constrangedora, a possível condenação de seus agentes pela prática de tortura.

A saída para esse impasse, segundo Todorov (2010), deu-se através do documento Torture Memo, em agosto de 2002, pelo Serviço de Assessoria Jurídica do Departamento de Justiça dos EUA, que, em linhas gerais, redefine o sentido de tortura, afrouxando as fronteiras das práticas consideradas coo tortura pelas convenções, situando os atos cometidos pelos agentes norte-americanos fora do conceito. Assim, “[...] Por um novo Memo, o Departamento da Justiça autorizou os agentes da CIA a espancar os prisioneiros, a expô-los a graus extremos de frio e de calor, a simular afogamento [...] (Todorov, 2010, p. 136)".

A discussão em torno da ressignificação do conceito de tortura trava-se nos salões intelectuais e políticos norte-americanos, na mídia, em declarações, em sua grande maioria a favor da "tortura", ou seja, das novas práticas necessárias para enfrentar a ameaça do terrorismo. A despeito das torturas terem sido descobertas, das acusações se amontoarem, a Casa Branca nega a prática de torturas em solo norteamericano, tais atos ocorreram nas prisões mantidas pelos Estados Unidos em outros países, as mais conhecidas, Bagram, no Afeganistão, Abu Ghraib, no Iraque e Guantánamo, em Cuba.

A guerra contra o terrorismo travada pelos Estados Unidos cria uma nova categoria jurídica, os "inimigos combatentes ilegais", indivíduos que podem ser presos sem a necessidade de respeito ao habeas corpus e sujeitos ao uso da tortura. Logo, devido às características do novo tipo de guerra e do inimigo a ser enfrentado, ressalta Todorov, produz-se uma situação na qual é "permitido" suspender as leis de período de paz. Já que nos encontramos no meio de uma guerra, mesmo que não seja convencional por não se tratar de uma guerra contra outro país, suspende-se também a aplicação da "guerra justa" e das Convenções Internacionais. Ora, se esta é uma guerra sem fim, como apresenta-nos Wood, esta situação já iniciada torna-se permanente, o respeito às leis nacionais, sobretudo com a nova categoria "inimigos combatentes ilegais", legitima a tortura, segundo Todorov, esta situação era prevista na elaboração do Torture Memo. 
[...] o memorando nega que os atos observados possam ser considerados como práticas de tortura; de fato, como vimos, ele sugere que tal prática existe apenas quando o prisioneiro perde uma perna ou um braço, sofre de uma incapacidade permanente para manter-se de pé, é atingido no fígado ou se torna incontinente para toda a vida [...] No plano mental, é necessário que a loucura provocada venha a instalar-se de forma definitiva: se não houver uma atenuação ao fim de alguns anos, então, poderá ser constatada, retrospectivamente, a prática da tortura. Em todos os outros casos, não há tortura e, por conseguinte, o governo dos Estados Unidos terá respeitado as Convenções Internacionais. (Todorov, 2010, p. 139).

Por mais que se tente mudar o conceito de tortura a fim de atender aos interesses norte-americanos e de seus aliados - que se beneficiam dos frutos obtidos por tais práticas desumanas -, não se pode mudar os atos que foram considerados como tortura ao longo da história, e que estão presentes nas Convenções Internacionais, à força da canetada, a partir de um documento legal, por mais bem escrito que ele esteja (Todorov, 2010). As mudanças na fronteira do que é considerado desumano em tempos de paz já foi rompida com o empreendimento da guerra sem fim, durante a administração Bush, que buscou tornar lícitas práticas que atentam contra a mínima dignidade humana. Entretanto, mesmo que tais atos sejam praticados além das fronteiras territoriais norteamericanas, ressalta Todorov, “[...] são efeito das decisões governamentais estadunidenses (2010, p. 141)".

\section{Considerações Finais}

O inimigo atual, que pode estar em qualquer lugar, desde a África Subsaariana até no subúrbio de Nova York, é apresentado pela retórica dominante como uma bestafera que se espalha de forma voraz pelo mundo e que, caso os Estados Unidos furtem-se de sua tarefa de proteger o mundo livre, colocará em risco os bens mais precisos aos norte-americanos e seus aliados. É, em grande medida, através desta justificativa que Washington defende seus métodos de tortura para extrair toda a informação necessária, pois é feito em defesa do mundo livre, uma crença que extrapola a retórica, que se encontra numa guerra contra o que há de mais cruel no mundo e, por isso, precisa lançar mão das ações necessárias, mesmo que a tortura faça parte destas. Busca-se, também, mostrar aos terroristas que o ocidente - imediatamente posicionando-os no que seria o oriente -, está pronto para responder a qualquer ameaça e a altura desta, intimidá-los a não se lançarem a novos atentados. 
Tais práticas explicam-se não pelos argumentos jurídicos invocados, nem pela obrigação de defender os princípios da democracia e os avanços da civilização ocidental, mas pelo medo que começou por subjugar os dirigentes do país e que eles acabaram transmitindo aos cidadãos. A ameaça, real ou imaginária, de perder a vida implica a conclusão: "Tudo é permitido". (Todorov, 2010, p. 146).

Por fim, seguindo a argumentação de Todorov, a política do medo produz mais ódio e ressentimento, sua resposta desmedida sejam bombardeios contra populações inocentes por veículos aéreos não tripulados (VANT), ocupações militares, táticas de regime change, quando claramente o terrorismo não é uma ameaça estatal, só reforçam o sentimento, do outro lado, de estarem empreendendo ações contraterroristas, respondendo as ações do terrorismo ocidental, isto é, do terrorismo de estado norteamericano e dos seus aliados na OTAN.

\footnotetext{
Essa política destrói as convicções mais profundas do mundo ocidental porque, para defender os valores democráticos tão apreciados por nós, somos levados a menosprezá-los! Como será possível regozijar-se com a vitória sobre um inimigo hediondo se, para vencê-lo, o vencedor acaba assumindo atitudes semelhantes ao adversário? (Todorov, 2010, p. 16).
}

As democracias sofrem grande risco de se converterem em estados policiais caso sejam contaminadas pelo medo paranoico, e é visando este objetivo que os Estados Unidos se valem internamente do terrorismo, obviamente, ele serve aos propósitos da política doméstica e externa. As novas leis antiterroristas dos Estados Unidos impõem um rígido controle interno, são, na verdade, leis de exceção, que ferem qualquer princípio democrático ao prender sem mandados judiciais a partir de qualquer suspeita, a detenção sem julgamento, grampos telefônicos e toda a parafernália de espionagem usada contra a população. "Os efeitos de uma "guerra contra o terrorismo" são particularmente perigosos porque, talvez, seja impossível interrompê-la; a suspensão das leis corre o risco de perdurar indefinidamente (2010, p. 128)". 


\section{Referências}

BIANCHI, Álvaro. Hegemonia em tempos de cólera: a difícil construção de uma ordem mundial. Revista Outubro, no 8, 2003.

CHOMSKY, Noam A. O Império Americano: hegemonia ou sobrevivência. Rio de Janeiro: Elsevier, 2004.

FIORI, José Luís. O Poder Americano. Petrópolis, Rj: Vozes, 2007.

HUNTINGTON, Samuel P. O choque das civilizações e a recomposição da ordem mundial. Rio de Janeiro: Objetiva, 1997.

MANN, Michael. O império da incoerência. Rio de Janeiro: Record, 2006.

TODOROV, Tzvetan. $O$ medo dos bárbaros: para além do choque das civilizações. Petrópolis, RJ: Vozes, 2010.

Os inimigos íntimos da democracia. São Paulo: Companhia das Letra, 2012.

WO0D, Ellen Meiksins. El imperio del capital. Madrid: El Viejo Topo, 2003. 